\title{
Número mais provável de Salmonella isoladas de carcaças de frango resfriadas
}

\author{
Most probable number of Salmonella isolated from refrigerated broiler carcasses
}

\author{
Anderlise Borsoi ${ }^{\text {I* }^{*}}$ Hamilton Luis de Souza Moraes II Carlos Tadeu Pippi Salle II \\ Vladimir Pinheiro do Nascimento II
}

\section{RESUMO}

A Salmonella permanece um importante problema na avicultura e, considerando os patógenos transmitidos por alimentos, aparece como um dos agentes principais em surtos de toxinfecções alimentares. Para auxiliar na avaliação de riscos em adquirir infecção alimentar via carne de frangos que sofreram cocção inadequada, ou através de contaminação cruzada a partir desses animais, torna-se importante determinar a extensão de contaminação por patógenos em carne crua. No presente trabalho, foram analisadas 180 carcaças de frangos resfriadas, adquiridas em varejos, para pesquisa de Salmonella com determinação do número de células da bactéria. Foi utilizado o método do número mais provável (NMP) nos ágares para isolamento verde brilhante com novobiocina (BGN) e xilose-lisina tergitol 4 (XLT4). Os resultados mostraram 12,2\% de ocorrência de Salmonella nas carcaças de frangos resfriadas e a média de NMP de Salmonella por $m L$, na leitura pelo ágar XLT4 foi de 2,7 células e no ágar BGN foi de 1,3 células. Os sorovares de Salmonella isolados das carcaças de frangos no estudo foram $\boldsymbol{S}$. Enteritidis, $\boldsymbol{S}$. Agona, $\boldsymbol{S}$. Rissen, $\boldsymbol{S}$. Heidelberg e $\boldsymbol{S}$. Livingstone. A análise dos resultados demonstrou existir um número variável de células de Salmonella contaminando as carcaças de frango resfriadas que estão à venda ao consumidor.

Palavras-chave: Salmonella, NMP, carcaça de frango, patógeno alimentar.

\section{ABSTRACT}

Salmonella in poultry remains an important worldwide problem, and among foodborne pathogens, the Salmonella appears as one of the most important outbreaks agents. To assess the risks of acquiring infection via undercooked poultry or cross contamination from chickens, it is important to determine the extent of the contamination on raw poultry with this pathogen. In this study, 180 refrigerated broiler carcasses, obtained from local stores, were assessed to recover Salmonella by the most probable number (MPN) method to quantify bacterias cells onto brilliant green agar with novobiocin $(B G N)$ and xylose lysin tergitol 4 agar (XLT4). The results showed 12,2\% occurrence of Salmonella by conventional microbiological method from refrigerated broiler carcasses. The MPN per ml rates was 2,7 cells on XLT4 agar and 1,3 cells on BGN agar plate. The Salmonella serovars isolated from broiler carcasses were $\boldsymbol{S}$. Enteritidis, $\boldsymbol{S}$. Agona, $\boldsymbol{S}$. Rissen, $\boldsymbol{S}$ Heidelberg and $\boldsymbol{S}$. Livingstone. Results analysis showed that could be a variable number of cells contaminating refrigerated broiler carcasses, which have been selling to the consumer.

Key words: Salmonella, MPN, broiler carcasses, foodborne pathogens.

\section{INTRODUÇÃO}

Em saúde pública, as salmonelas destacamse com grande importância pela sua ampla e variada ocorrência no homem e em animais (mamíferos, répteis e aves), sendo que as aves ocupam o ponto central na epidemiologia das salmoneloses entéricas, representando um reservatório de grande importância sanitária e difícil controle. Nestes, o estado de portador é o fator epidemiológico mais destacado e a falta de

'Curso de Medicina Veterinária, Universidade Tuiuti do Paraná (UTP), Faculdade de Ciências Biológicas e da Saúde (FACBS), Rua Sydnei Rangel Santos, 238, Bairro Santo Inácio, 821010-330, Curitiba, PR, Brasil. E-mail: anderliseb@yahoo.com.br. Autor para correspondência.

"Centro de Diagnóstico e Pesquisa em Patologia Aviária (CDPA), Faculdade de Medicina Veterinária, Universidade Federal do Rio Grande do Sul (UFRGS), Porto Alegre, RS, Brasil. 
sintomas e as dificuldades técnicas para sua detecção, antes ou durante a inspeção no abate, convertem-nos em fonte contínua de contaminação do meio ambiente e, portanto, dos produtos de origem animal (RODRIGUES, 2005). A Salmonella é um dos mais importantes patógenos mundialmente distribuídos, associado à carne de frango e seus produtos derivados (BRYAN \& DOYLE, 1995). Estudos a respeito de prevalência de Salmonella em carcaças de frangos no Brasil, apresentam dados diferenciados, como na cidade de Descalvado, São Paulo, em que o resultado da pesquisa de Salmonella em carcaças foi ausência da bactéria nas amostras (CARDOSO et al., 2005), ou, ainda em São Paulo, porém no município de Jaboticabal, onde 150 carcaças congeladas foram analisadas e o percentual de positividade para Salmonella estabelecido foi 32,0\% (SANTOS et al., 2000). Dados do Rio Grande do Sul, apresentados pela pesquisa de NASCIMENTO et al. (2003), citam contaminação por Salmonella de $15,1 \%$ em carcaças e $26,1 \%$ nas amostras de partes de frangos. Outro estudo no Rio Grande do Sul contou a avaliação do processo higiênico-sanitário de abate de frangos, em três diferentes matadouros, sendo que as carcaças analisadas antes e depois do chiller apresentaram, respectivamente, $31,7 \%$ e $20,0 \%$ de contaminação por salmonelas (DICKEL, 2004). Apesar da citada disponibilidade de dados relativos à incidência de salmonelas em carne de aves, a determinação da extensão desta contaminação, ou seja, a quantificação de células é relatada em poucos estudos. Conhecer o número de células de Salmonella presentes na carne de aves é um ponto importante para auxiliar a análise de riscos em adquirir infecções alimentares, via consumo desta carne mal cozida, ou através de contaminação cruzada entre carne de aves crua e outros produtos que estão sendo manipulados (JØRGENSEN et al., 2002). Dois estudos publicados nos últimos anos determinaram metodologias para a contagem de Salmonella. No estudo de UYTTENDAELE et al. (1998), foram utilizadas carcaças de aves congeladas e outros produtos derivados para contagem de bactérias semiquantitativamente. O critério adotado para determinar o nível de contaminação foi de 1 ufc $100 \mathrm{~cm}^{-2}$ ou $25 \mathrm{~cm}^{2}$ e 25 gramas, classificadas como baixa contaminação e mais de 1 ufc $\mathrm{cm}^{-2}$ ou 25 gramas, classificada como alta contaminação. Em 2001, DUFRENNE et al. publicaram uma metodologia quantitativa para determinação do NMP de Campylobacter e Salmonella em carcaças de frangos, sem diluições seriadas a partir da amostra inicial. Com esta metodologia, usaram como critério de classificação uma escala de células por carcaça, distribuidas em três

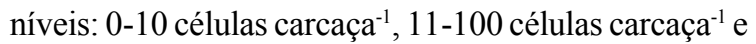
$>1.100$ células carcaça $^{-1}$ como números mais prováveis. O presente estudo teve como base a metodologia descrita por DUFRENNE et al. (2001), utilizada com o objetivo de verificar a presença e estimar o número mais provável de células de Salmonella em carcaças de frangos resfriadas.

\section{MATERIAL E MÉTODOS}

Carcaças de frango resfriadas a venda em varejos foram obtidas em número de 10 por semana em um mesmo turno de abate. As coletas de carcaças ocorreram de fevereiro a novembro de 2004 e as marcas foram definidas em função da disponibilidade semanal do material nos varejos da região Nordeste do Rio Grande do Sul. A partir da marca "A", foram adquiridas 55 carcaças, marca "B" 50 carcaças e marca "C" 75 carcaças, totalizando 180 amostras. $\mathrm{O}$ transporte foi realizado em caixas isotérmicas e o início do processamento ocorria em 20 minutos após a coleta das amostras. A contagem de Salmonella foi realizada pelo método do número mais provável (NMP) de células bacterianas por $\mathrm{mL}$ ou $\mathrm{g}$, descrito por DUFRENNE et al. (2001). Esse método foi adaptado para menor volume de meio de cultura para enxágue inicial das carcaças (COX et al., 1981) e inclusão do ágar xilose lisina tergitol 4 (XLT4), para leitura dos isolados (YNTERIAN, 2003). Em seguida, elas foram removidas de sua embalagem original e colocadas em sacos de polietileno para aferição do peso e início do processo. $\mathrm{O}$ enxágue foi realizado com $150 \mathrm{~mL}$ de água peptonada tamponada (AP) por $2 \mathrm{~min}$. Após o enxágue, a AP foi dividida em nove tubos: $3 \times 30 \mathrm{~mL}, 3 \times 3 \mathrm{~mL}$ e $3 \times 0,3 \mathrm{~mL}$ (aos tubos com $0,3 \mathrm{~mL}$, foram adicionados $3 \mathrm{~mL}$ de AP) e incubados a $37^{\circ} \mathrm{C}$ por $18 \pm 2 \mathrm{~h}$. A partir das culturas de AP, $0,1 \mathrm{~mL}$ de cada um dos nove tubos, foi adicionado a outros nove tubos com $10 \mathrm{~mL}$ de caldo Rappaport Vassiliadis (RV) e incubados por $24 \pm 2 \mathrm{~h}$ a $42^{\circ} \mathrm{C}$. As culturas de RV foram estriadas em ágar verde brilhante com novobiocina (BGN) e ágar xilose lisina tergitol 4 (XLT4), resultando 18 placas de cultura por amostra e incubadas por $24 \pm 2 \mathrm{~h}$ a $37^{\circ} \mathrm{C}$. A leitura das placas positivas foi realizada em série de três placas, conforme as diluições iniciais. A composição final das três séries de leitura foi comparada à tabela de DeMAN (1983), na qualo NMP por grama ou $\mathrm{mL}$ está estabelecido com diferentes limites de confiança, sendo $95 \%$ o limite adotado nesta pesquisa. Testes bioquímicos e sorológicos foram realizados nas colônias suspeitas. A identificação final das colônias positivas foi realizada no Laboratório de Enterobactérias da Fundação Oswaldo Cruz (FIOCRUZ). 


\section{RESULTADOS}

O percentual de isolamneto de Salmonella em carcaças de frango resfriadas encontrado a partir das três diferentes marcas comerciais analisadas foi de 12,2\%. O NMP $\mathrm{mL}^{-1}$ de Salmonella foi determinado nos meios de cultura XLT4 e BGN, apresentando médias de contagens de 2,7NMP mL $\mathrm{mL}^{-1}$ 1,3 $\mathrm{NMP} \mathrm{mL}^{-1}$, respectivamente. O NMP por carcaças foi calculado a partir da fórmula descrita por DUFRENNE et al. (2001): peso da carcaça x NMP (tabela) / maior volume de amostragem, resultando valores 0 a mais de 1100 células por $\mathrm{mL}$, apresentados na tabela 1 . Os resultados nos meios XLT4 e BGN diferiram significativamente para a quantidade de células em recuperadas nas mesmas carcaças $(\mathrm{P}=0,027)$. Os sorovares e frequência de isolamento de Salmonella nas amostras foram: $\boldsymbol{S}$. Enteritidis (31.8\%,), S. Agona (31.8\%,), $\boldsymbol{S}$. Rissen $(22,7 \%),, \boldsymbol{S}$. Heidelberg $(9,0 \%)$ e $\boldsymbol{S}$. Livinsgtone $(4,5 \%)$. No presente trabalho, houve diferença nos isolamentos por marca e estão apresentados na tabela 2. Os resultados foram analisados pelos métodos Chiquadrado e Teste $t$ de Student, através do programa SPSS for Windows, versão 10.05;1999.

\section{DISCUSSÃO}

A Salmonella é comsiderado um dos principais patógenos envolvidos em doenças transmitidas por alimnetos mundialmente. No Brasil, dos 2.974 surtos de toxinfecções alimentares em humanos (nos anos de 1999 a 2008) causados pelos agentes mais frequentemente envolvidos, as Salmonella spp foram responsáveis por $42,9 \%$ das ocorrências e o sorovar Salmonella Enteritidis, por mais $4,1 \%$ dos surtos. Em 460 pessoas acometidas de toxinfeccção por Salmonella, 378 tiveram carne de aves ou ovos como alimento envolvido nos surtos (SVS, 2008). Tais dados demonstram que a presença do agente em produtos avícolas figura importância no Brasil.

Este trabalho apresentou $12,2 \%$ de incidência, colocando-se este valor entre os diversos dados de incidência de Salmonella em carcaças de

Tabela 1 - NMP de Salmonella detectados em carcaças de frango de corte resfriadas e percentual de contagem nos meios de cultura XLT4 e BGN.

\begin{tabular}{lll}
\hline NMP/ carcaça & XLT4 $(\%)$ & BGN $(\%)$ \\
\hline $0-10$ & 0 & 0 \\
$11-100$ & 45,45 & 64,70 \\
$101-1100$ & 54,55 & 35,30 \\
$>1100$ & 13,63 & 0 \\
\hline
\end{tabular}

frango citados na literatura de diferentes países, com percentuais que variam de $2,9 \%$ a $68,6 \%$ (SIMMONS et al. 2003). A incidência de $12,2 \%$ neste trabalho está próxima aos percentuais encontrados por DUFRENNE et al. (2001), de $13,5 \%$ de positividade e NASCIMENTO et al. (2003) que relatam $15,1 \%$ de positividade para Salmonella. Contudo, a ocorrência encontrada difere de análises realizadas no Brasil, citadas por SANTOS et al. (2003), que encontraram 32,0\% de contaminação, DICKEL (2004), 20,0\% e CARDOSO et al. (2005) que não detectaram Salmonella nas amostras analisadas. Os diferentes resultados das pesquisas estão de acordo com a citação de que o percentual de Salmonella em carcaças pode variar, dentre outros fatores, devido à metodologia de deteç̧ão utilizada (UYTTENDAELE et al., 1998), contaminação das aves pré-abate e sistema e regulamentação de abate das aves nos diferentes países.

Os sorovares de Salmonella identificados nas amostras foram $\boldsymbol{S}$. Enteritidis e $\boldsymbol{S}$. Agona como mais prevalentes, seguidos por $\boldsymbol{S}$. Rissen, $\boldsymbol{S}$. Heidelberg e $\boldsymbol{S}$. Livingtone. Tais constatações também foram identificados em estudos realizados na mesma região geográfica, nas pesquisas de NASCIMENTO et al. (2003), as quais descrevem os $\boldsymbol{S}$. Enteritidis com $51,0 \%$ de frequência de aparecimento, $S$. Hadar com $26,0 \%$ e $S$. Heidelberg apresentando $11,0 \%$. Além desses casos, DICKEL (2004) identificou maior variedade de sorovares, sendo $S$. Heidelberg de maior frequência de aparecimento em $63,9 \%$ dos isolados, seguido de $\boldsymbol{S}$. Enteritidis com $31,09 \%, S$. Whorthington apresentando $2,1 \%$ e $\boldsymbol{S}$. Tennessee também com $2,1 \%$. A maior ocorrência do sorovar Enteritidis nesta pesquisa ressalta a importância de carcaças de frango como potencial veículo de infecções alimentares em humanos, tendo em vista os dados sobre pessoas acomentidas em surtos no Brasil, citado anteriormente. Ainda, pesquisa divulgada pela ANVISA aponta os sorovares $\boldsymbol{S}$. Enteritidis, $\boldsymbol{S}$. Infantis, $\boldsymbol{S}$. Typhimurium, $\boldsymbol{S}$. Heidelberg e $\boldsymbol{S}$.Mbandaka como mais prevalentes em carcaças congeladas no Brasil (PREBAF, 2008). Nos Estados Unidos e Europa, todos os sorovares encontrados na presente pesquisa foram relatados como causadores de infecções alimentares em humanos a partir de diferentes fontes (GUERIN et al., 2004; CDC, 2010). A respeito das infecções em humanos, de acordo com POPPE (1996), há evidências de que a dose infectante de 10 a 1000 células de Salmonella possam causar infecções em humanos.

Os NMPs por carcaça determinados na tabela 1 diferem dos resultados das pesquisas de vários autores. Elas apontam o fato de ser muito baixo o número de células de Salmonella que contaminam uma 
Tabela 2 - Frequência de isolamento de Salmonella nas diferentes marcas analisadas.

\begin{tabular}{llll}
\hline $\begin{array}{l}\text { Sorovares de } \\
\text { Salmonella }\end{array}$ & \multicolumn{3}{c}{ Marcas e frequência de aparecimento } \\
& \multicolumn{4}{c}{ dos sorovares isolados } \\
\hline & A (\%) & B (\%) & C (\%) \\
Enteritidis & - & - & 31,81 \\
Agona & - & - & 31,81 \\
Rissen & - & 4,54 & 18,16 \\
Heidelberg & 9,10 & - & - \\
Livingstone & 4,54 & - & - \\
\hline
\end{tabular}

carcaça, ou seja, menor que 100NMP por carcaça (BOKANYI et al., 1990; IZAT et al., 1990; WHITMORE, 1993; NASCIMENTO, 1995; CARRAMIÑNAN et al., 1997; CARDOSO et al., 2005).

O presente estudo foi elaborado com base na metodologia de DUFRENNE et al. (2001), porém seus resultados diferem dos encontrados pelos autores. Eles citam menores níveis de contaminação das carcaças, ou seja, 89,0\% delas apresentaram contaminação de 0 a 10 células; $9,0 \%$, níveis de 11 a 100 células e $2,0 \%$ de carcaças contaminadas com $>1100$ células de Salmonella, estando esses valores de NMP determinados a partir do meio de cultura BGN. O aumento da porcentagem de carcaças contaminadas com $>100$ células, apresentado neste estudo, pode ser explicado, possivelmente, por alguns fatores principais que incluem o volume de enxágue das carcaças (menor que o volume utilizado pelos autores), promovendo aumento da concentração das células presentes no material e promovendo menor desperdício de água de enxágue (COX et al., 1981). Outro fator a considerar, quando analisados os maiores valores de NMP encontrados na presente pesquisa, é o processo de abate das aves, visto que os níveis de cloro do chiller diferem, por legislação, entre os países, além de que as concentrações de cloro livre podem afetar diretamente a contagem dos microrganismos.

A constatação de presente NMP nas carcaças auxilia na determinação do risco para sua própria redução, além do controle de Salmonella nas indústrias de alimentos, sendo que a quantificação de patógenos foi citada em reunião técnica da FAO e OMS para controle de Salmonella e Campylobacter em carne de frangos, como necessário para reduzir riscos à saúde do consumidor (FAO/WHO, 2009).

\section{CONCLUSÃO}

Os procedimentos adotados na modificação da técnica promoveram a detecção de uma maior porcentagem de carcaças contaminadas com $>100$ células Salmonella neste trabalho, frente ao trabalho com metodologia original. A contaminação por Salmonella em carne de frango aparece como um problema em potencial e o risco de contaminação cruzada gerado pode ser proporcional ao número de células presentes na carne de frango in natura (JØRGENSEN et al., 2002). Desse modo, estudos para a quantificação do nível de infecção por Salmonella em carcaças de frango auxiliam na avaliação da exposição ao risco, que traduz a necessidade de ações a níveis de indústria e consumidor

\section{REFERÊNCIAS}

BOKANY, R. P. et al. Isolation and characterization of Salmonella from broiler carcass or parts. Poultry Science, v.69, p.492-598, 1990.

BRYAN, F.L.; DOYLE, M.P. Health risks and consequences of Salmonella and Campylobacter jejuni in raw poultry. Journal of Food Protection, v.58, n.3, p.326-344, 1995.

CARRAMIÑANA, J.J. et al. Salmonella incidence and distribution of serotypes throughout processing in a Spanish poultry slaughterhouse. Journal of Food Protection, v.60, n.11, p.1312-1317, 1997.

CARDOSO, A.L.S.P. et al. Pesquisa de Salmonella spp., coliformes totais, coliformes fecais, mesófilos, em carcaças e cortes de frango. Higiene Alimentar, v.19, n.128, p.144150,2005 .

CDC. Preliminary FoodNet Data on the Incidence of Infection with Pathogens Transmitted Commonly Through Food - 10 States, 2009. United States of America, v.59, n.14, p.418422, 2010. Disponível em: <http://www.cdc.gov/mmwr/pdf/ wk/mm5914.pdf>. Acesso em: set. 2010.

COX, N.A. et al. Sampling of broiler carcass for Salmonella whit low volume water rinse. Poultry Science, v.60, p.768770, 1981.

DeMAN, J.C. MNP tables, corrected. European Journal of Applied Microbiology, v.17, p.301-305. 1983.

DICKEL, E.L. Utilização da técnica microbiológica convencional, reação em cadeia pela polimerase (PCR) e ensaio imunoenzimático (ELISA) no monitoramento de Salmonella em carcaças de frango para o controle higiênico-sanitáriodo processo de abate. 2004. 137f. Tese (Doutorado em Medicina Veterinária) - Programa de Pósgraduação em Ciências Veterinárias, Universidade Federal do Rio Grande do Sul, RS.

DUFRENNE, J. et al. Quantification of the contamination of chicken and chicken products in The Netherlands with Salmonella and Campylobacter. Journal of Food Protection, v.64, n.4, p.538-541, 2001. 
FAO/WHO. Technical Meeting on Salmonella and Campylobacter in chicken meat. Rome, 2009. Disponível em: <http://www.worldvet.org/node/5236>. Acesso em: jul. 2009.

GUERIN,P.J. et al. Outbreak of Salmonella Livingstone infection in Norway and Sweden do contaminated processed fish products. Epidemiology and Infections, v.132, n.5, p.889-895, 2004.

IZAT, A.L. et al. Incidence, number and serotypes of Salmonella on frozen broiler chickens retail. Poultry Science, v.70, p.1438-1440, 1991.

JØRGENSEN, F. et al. Prevalence and numbers of Salmonella and Campylobacter spp. on raw, whole chickens in relation to sampling methods. International Journal of Food Microbiology, v.76, p.151-164, 2002.

NASCIMENTO, V.P. Salmonelose aviárias: uma revisão. In: SIMPÓSIO DE PRODUÇÃO DE MATRIZES DE CORTE, 1995, Chapecó. Anais... Chapecó: Associação Catarinense de Avicultura,1995. p.51-61.

POOPE, C. Salmonella Enteritidis in Canada. International Journal of Food Microbiology, v.21, p.1-5, 1994.

PREBAF. Relatório do Monitoramento da prevalência e do perfil de suscetibilidade as antimicrobianos em enterococos e salmonelas isolados de carcaças de frango congeladas comercializadas no Brasil. Brasil. $188 \mathrm{p}$. Disponível em: <http://www.anvisa.gov.br/ALIMENTOS/ relatorios/relatorioprebaf.pdf $>$. Acesso em: set. 2008.
RODRIGUES, D.P. Ecologia e prevalência de Salmonella spp. em aves e material avícola no Brasil. In: CONFERÊNCIA APINCO DE CIÊNCIA E TECNOLOGIA AVÍCOLAS, 2005, Santos, SP. Anais... Campinas: FACTA, 2005. V.2, p.223228.

SANTOS, D.M.S. et al. Salmonella em carcaças de frango congeladas. Pesquisa Veterinária Brasileira,v.20, p.39$42,2000$.

SANTOS, L.R. et al. Phagetypes of Salmonella Enteritidis isolated from clinical food samples, and from broiler carcasses in Southern Brazil. Revista do Instituto de Medicina Tropical, v.45, n.1, p.1-4, 2003.

SIMMONS, M. et al. Recovery of Salmonella from retail broilers by a whole-carcass enrichment procedure. Journal of Food Protection, v.66, n.3, p.446-450, 2003.

SVS. Análise Epidemiológica dos Surtos de Doenças Transmitidas por Alimentos no Brasil. Brasil, 2008. Disponível em: <http://portal.saude.gov.br/portal/arquivos/pdf/ surtos_dta_15.pdf $>$. Acesso em: out. 2009.

UYTTENDAELE, M.R. et al. Prevalence of Salmonella in poultry carcasses and their products in Belgium. International Journal of Food Microbiology, v.40, p.1-8, 1998.

WHITTMORE, A.D. A modified most probable number technique to enumerate total aerobes, enterobacteriaceae and Salmonella on poultry carcass after whole rinse procedure. Poultry Science, v.72, p.2353-2357, 1993. 